\title{
Diagnose Pathogens in Drinking Water via Magnetic Surface-Enhanced Raman Scattering (SERS) Assay
}

\author{
Hanbing $\mathrm{Li}^{\mathrm{a}}$, Cui Li ${ }^{\mathrm{a}, \mathrm{b}}$, Francis L. Martin ${ }^{\mathrm{a}}$, Dayi Zhang ${ }^{\mathrm{a},{ }^{*}}$ \\ ${ }^{a}$ Lancaster Environment Centre, Lancaster University, Lancaster LA1 2YQ, UK \\ ${ }^{b}$ Key Laboratory of Urban Pollutant Conversion, Institute of Urban Environment, Chinese \\ Academy of Sciences, Xiamen 361021, China
}

Corresponding author:

Dr Dayi Zhang

Email: $\underline{\text { d.zhang@lancaster.ac.uk }}$

Tel: $+44(0) 7588858333$

\begin{abstract}
Rapid identification and diagnosis of bacteria and other microorganisms is a great challenge for drinking water safety due to the increasing frequency of pathogenic infections. Raman spectroscopy is a non-destructive tool to characterize the biochemical fingerprints of bacterial cells and its signal can be improved by surface-enhanced Raman scattering (SERS). Thus, Raman scattering has a huge potential in fast diagnosis of pathogens in drinking water, with low cost and high reproducibility. In this work, we developed a novel fast diagnosis method to detect aquatic pathogens via magnetic SERS assay. With chemical co-precipitation synthesis and surface glucose reduction, the silver coated magnetic nanoparticles (Ag@MNPs) had a well-developed core-shell structure and high efficiency to capture bacterial cells.Ag@MNPs achieved 103 enhancement factor for rhodamine 6G and the limit of detection was $10^{-9} \mathrm{M}$. The magnetic SERS assay also successfully detected various bacteria (A. baylyi and E. coli) with high sensitivity $\left(10^{5} \mathrm{CFU} / \mathrm{mL}\right)$. This platform provided a promising and easy-operation approach for pathogen detection for food and drinking water safety.
\end{abstract}

Keywords: magnetic nanoparticles (MNPs), silver-coated MNPs (Ag@MNPs), Raman spectroscopy, surface-enhanced Raman scattering (SERS) 


\section{Introduction}

Millions of cases of diseases are caused by pathogens in drinking water (Szewzyk et al., 2000; World Health Organization, 2011), though they exist at low concentration and are hard to identify. Many diagnosis methods therefore are developed to rapidly detect these pathogens (Rompre et al., 2002), as polymerase chain reaction (PCR) (Dharmasiri et al., 2010; Ibekwe et al., 2002), colony forming (Penna et al., 2002) and staining (Lehtola et al., 2005), but the majority of them are time-consuming and not suitable for worldwide application in practice. It raises great chances for novel technical development for water resource protection and water treatment to rapidly recognize aquatic pathogens addressing drinking water safety issues.

Magnetic nanoparticles (MNPs) have been widely applied in biological science for its affinity to biological molecules (Huang et al., 2010), such as bioenergy recovery (Lin et al., 2015), drug delivery (Sun et al., 2008) and drinking water purification (Xu et al., 2014). In environmental science, most relative research has addressed the magnetisms improvement (Ennen et al., 2012; Ozdemir et al., 2012) or surface modification to enhance bacteria capturing efficiency (Luis Corchero \& Villaverde, 2009). There is limited work on how to use MNPs as a diagnosis tool in quantifying pathogens in drinking water.

Raman microspectroscopy is a promising method for bacterial detection (Chan et al., 2004). To improve the signal intensity, surface-enhanced Raman scattering (SERS) was developed (Porter et al., 2008) and used in diagnosis of pathogens in drinking water (Jarvis \& Goodacre, 2004). However, direct application of SERS requires the mixture and separation of bacterial cells with suspended $\mathrm{Ag} / \mathrm{Au}$ nanoparticles (Grow et al., 2003) or bacteria capture on mesostructured materials supported with $\mathrm{Ag} / \mathrm{Au}$ nanoparticles (Wang et al., 2015). The former approach suffers from the difficulties in recovering $\mathrm{Ag} / \mathrm{Au}$ nanoparticles from the samples, and the latter one faces the challenges that the low cell counts in water samples means the low capture efficiency. Considering the magnetic enrichment of MNPs and SERS active substrate $\mathrm{Ag} / \mathrm{Au}$, some surface modification has been applied to combine these two types of nanomaterials together in detecting pollutants (An et al., 2012), biomarkers (Yang et al., 2015) or pathogens (Zhang et al., 2012).

Here, we developed a novel high-sensitive screening method for rapid detection of pathogens in drinking water with silver-coated MNPs (Ag@MNPs) by magnetic capturing and SERS diagnosis. The limit of detection for bacteria was significantly improved, attributing to the 
magnetic enrichment and SERS signal enhancement which were simultaneously achieved by Ag@MNPs.

\section{Experimental Section}

\subsection{Synthesis of silver coated magnetic nanoparticles}

The synthesis of MNPs followed chemical co-precipitation (Zhang et al., 2011) and Ag surface coating was achieved by glucose reduction (Mandal et al., 2005; Sau \& Murphy, 2004). Briefly, $1.0 \mathrm{M} \mathrm{FeCl}_{3}(2.0 \mathrm{~mL}$ in $1.0 \mathrm{M} \mathrm{HCl})$ and $2.0 \mathrm{M} \mathrm{FeCl}_{2}(0.5 \mathrm{~mL}$ in $1.0 \mathrm{M} \mathrm{HCl})$ were mixed and homologized, with $25 \mathrm{~mL} \mathrm{NaOH}(2.5 \mathrm{M})$ dropwisely added until the appearance of dark iron oxide precipitates. With further $30 \mathrm{~min}$ vortex, the iron oxide suspension was separated by permanent magnet and washed by deionized water until neutral $\mathrm{pH}$. The synthesized MNPs were further coated with silver as SERS active substrate by mixing $1 \mathrm{~mL}$ MNPs with a proper weight of $\mathrm{Ag}_{2} \mathrm{SO}_{4}$ to reach a 1:20 (MNPs: $\left.\mathrm{Ag}_{2} \mathrm{SO}_{4}\right)$ molar ratio. After adding $0.5 \mathrm{~g}$ glucose and sonicated for $15 \mathrm{~min}$, the suspension was heated to $80^{\circ} \mathrm{C}$ in a water bath and slowly stirred for 1 hour. The MNPs turned from dark into brownish colour, and the Ag@MNPs were further stirred for 30 minutes until room temperature. Separated by permanent magnet and washed by deionized water, Ag@MNPs were stored for further experiment and analysis.

\subsection{Bacterial strains and cultivation}

In this study, the two bacterial strains were Acinetobacter baylyi ADP1 and Escherichia coli JM109, with close phylotypic relationship to clinical pathogens Acinetobacter baumannii and Escherichia coli $\mathrm{O} 157: \mathrm{H7}$. The strains were grown in sterile Lysogeny Broth medium for 16 hours, at $30^{\circ} \mathrm{C}$ for $A$. baylyi and $37^{\circ} \mathrm{C}$ for E. coli, respectively. The cell suspensions were further centrifuged at 4,000 rpm for $5 \mathrm{~min}$ and washed three times by sterile deionized water. Afterwards, the bacterial cells were serially diluted to $10^{8} \mathrm{CFU} / \mathrm{mL}$ and $10^{5} \mathrm{CFU} / \mathrm{mL}$ for Raman microspectroscopy analysis.

\subsection{Bacteria capture and Raman microspectroscopy analysis}

By adding the MNPs or Ag@MNPs suspension (5 $\mu \mathrm{L}$ ) into diluted cell suspension or rhodamine 6G (R6G) samples $(1 \mathrm{~mL})$, the mixture was cultivated for $10 \mathrm{~min}$ and the magnetic pellets were harvested by permanent magnet. The pellet was then washed by deionized water and ethanol five times for Raman microspectroscopy analysis, obtained by 
InVia Raman microscopy (Horiba, UK) with 785-nm excitation laser (100\% and $1 \%$ power for normal Raman and SERS spectrum respectively), 10 second exposure time and a 500$2000 \mathrm{~cm}^{-1}$ spectral range. For all the spectral measurement, at least twenty biological replicates were randomly selected and analysed.

\subsection{Chemical and biological analysis}

The phase identification of synthesized MNPs and Ag@MNPs nanocomposites was carried out by X-ray diffraction (XRD, D8-Advance, Bruker, UK). The magnetic properties were measured by a vibrating sample magnetometer (VSM, Lake Shore, 7304 , USA) at $25^{\circ} \mathrm{C}$ and in a magnetic field varying from $-1.7 \mathrm{~T}$ to $+1.7 \mathrm{~T}$. The Raman spectra were first subtracted by the IRootLab Matlab interface for spectra truncation between $500-2000 \mathrm{~cm}^{-1}$ and baseline correction (Martin et al., 2010). The Raman signal intensity of R6G was calculated at the bands of 1514, 1365, 1310, 1184, 774 and $614 \mathrm{~cm}^{-1}$. To calculate the capture efficiency of MNPs and Ag@MNPs towards bacteria cells, the number of total and magnetic-free bacteria was determined by quantitative polymerase chain reaction (qPCR) respectively according to our previous study (Zhao et al., 2016). The $16 \mathrm{~S}$ rRNA primer pair was 341F (5'CCTACGGGNGGCWGCAG-3') and 802R (5'-TACNVGGGTATCTAATCC-3'). Each 10 $\mu \mathrm{L}$ qPCR reaction system contained $1 \mu \mathrm{L}$ of each primer, $1 \mu \mathrm{L}$ DNA template, $2 \mu \mathrm{L}$ molecular water and $5 \mu \mathrm{L}$ iTaq ${ }^{\mathrm{TM}}$ Universal SYBR ${ }^{\circledR}$ Green Supermix (BioRad, USA). The thermos cycling parameters followed: $94^{\circ} \mathrm{C}$ for $3 \mathrm{~min} ; 34$ cycles of $94^{\circ} \mathrm{C}$ for $45 \mathrm{~s}, 52^{\circ} \mathrm{C}$ for 45 $\mathrm{s}, 72^{\circ} \mathrm{C}$ for $45 \mathrm{~s}$ and $80^{\circ} \mathrm{C}$ for $15 \mathrm{~s}$ for fluorescence data acquisition. Standard curves were obtained with serial dilutions of quantified plasmid DNA containing the fragment of $16 \mathrm{~S}$ rRNA.

\section{Results and Discussion}

\subsection{Characterization of silver-coated magnetic nanoparticles}

The XRD pattern (Fig. 1A) identified the diffraction peaks of synthesized MNPs as $2 \theta=30.0^{\circ}$, $35.4^{\circ}, 43.2^{\circ}, 53.6^{\circ}, 57.1^{\circ}$ and $62.7^{\circ}$, indexed to (220), (311), (400), (422), (511) and (440) lattice planes (Zhao et al., 2016). For Ag@MNPs, the key diffraction peaks were $2 \theta=38.1^{\circ}$, $44.3^{\circ}$ and $64.4^{\circ}$, indexed to (111), (200) and (220) lattice planes (López Pérez et al., 1997). The characteristic diffraction peaks of pure MNPs were significantly weakened and hardly distinguished on Ag@MNPs (black triangle in Fig. 1A). The results proved that Ag@MNPs 
nanocomposites had a well core-shell structure with fine Ag-coating on MNPs surface. Our magnetization test further illustrated that both the magnetization curves behaved the $S$ shape (Figure 1B). The highest saturation magnetization of MNPs and Ag@MNPs was 44.3 emu/g and $37.9 \mathrm{emu} / \mathrm{g}$ respectively. It was worth mentioning that the magnetic separation of MNPs and Ag@MNPs were similar, and both supernatants were completely transparent. These results indicated limited magnetism loss after Ag-coating and the strong magnetic harvesting capacity of Ag@MNPs, suggesting that Ag@MNPs could be effectively controlled by magnetic field.

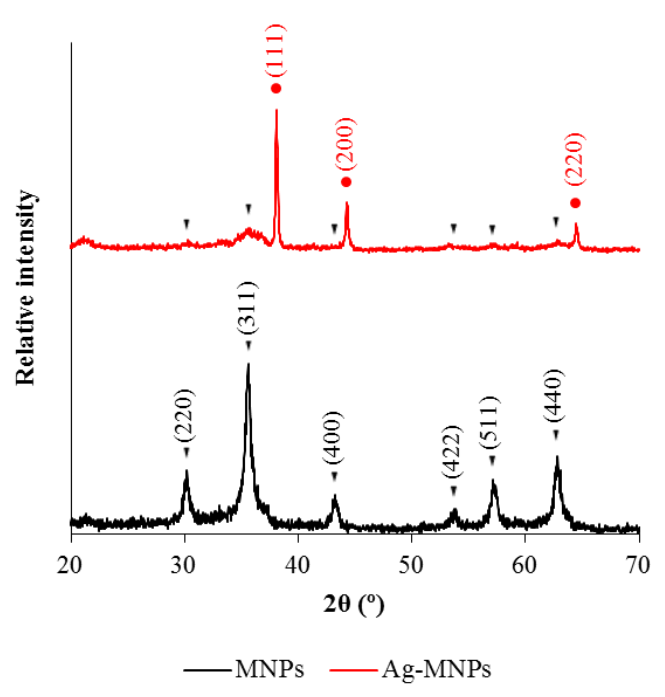

(A)

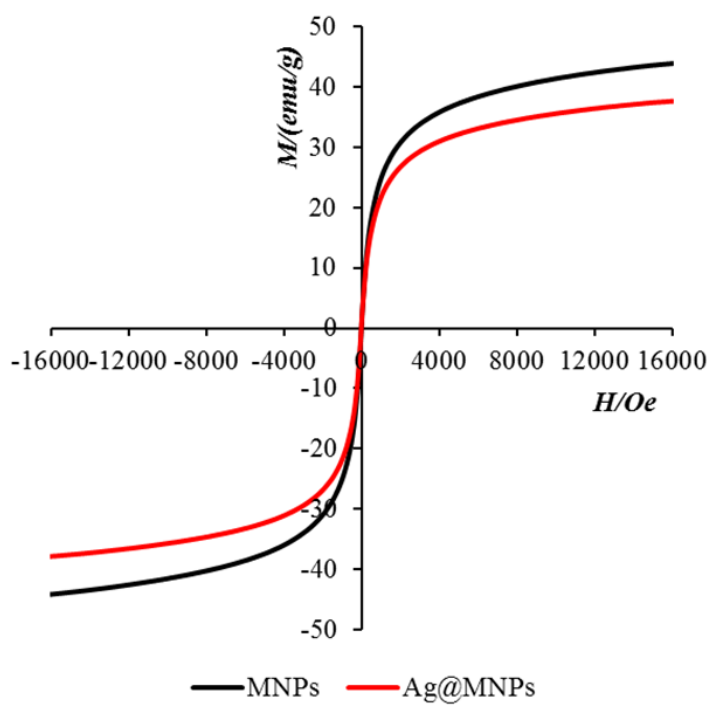

(B)

Fig. 1. The XRD pattern (A) and magnetization curve (B) of MNPs and Ag@MNPs nanocomposites.

Ag@MNPs maintained high capture efficiency for bacterial cells (Fig. 2). From the results of qPCR, the original concentration of $E$. coli and A. baylyi suspension was $1.03 \times 10^{9} \mathrm{CFU} / \mathrm{mL}$ and $1.79 \times 10^{8} \mathrm{CFU} / \mathrm{mL}$, respectively. After magnetic separation by MNPs and Ag@MNPs, the amount of magnetic-free bacteria in the supernatant was $5.0 \times 10^{4} \mathrm{CFU} / \mathrm{mL}$ (MNPs) and

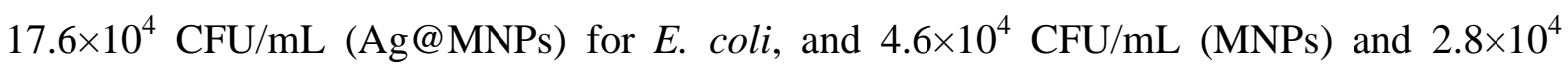
CFU/mL (Ag@MNPs) for A. baylyi, respectively. The capture efficiency of MNPs and Ag@MNPs were both higher than $99.5 \%$ for E. coli and $99.9 \%$ for A. baylyi. Such similar capture efficiency indicated that: 1) Ag-coating showed limited impacts on the surface electrostatic properties of MNPs and the electrostatic attraction was attributed to the positively charged MNPs towards negative bacterial cells; 2) Ag@MNPs capturing was nonselective and could be used for various bacterial strains. Different from previous research 
which employed polymers to achieve high bacteria capture efficiency (Huang et al., 2010), our method directly coated Ag on naked MNPs and minimized the disturbance of coating polymers on SERS signal. Besides, we did not introduce silicon dioxide shell for surface Agor Au-coating (Shen et al., 2013) and therefore maintained the high magnetism and strong affinity to bacteria of Ag@MNPs. Meanwhile, Ag@MNPs were not further functionalized with antibody conjugation to target specific bacteria as previous study (Chu et al., 2013; Joo et al., 2012). It broadened the application area of this magnetic assay for all types of pathogen detection in drinking water by direct electrostatic attraction. Given these advantages, the Ag@MNPs assay was therefore easy to be used for bacteria capture and magnetic enrichment for further SERS analysis.

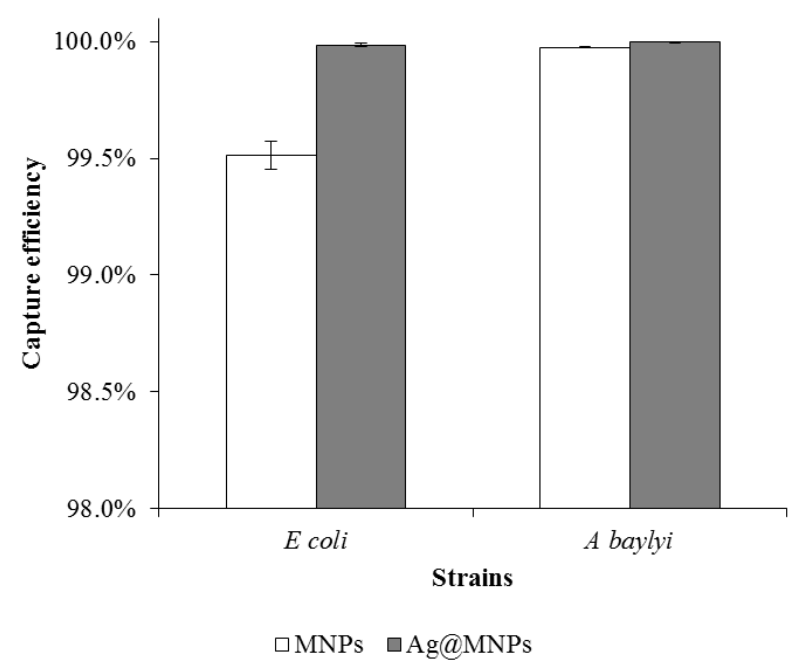

Fig. 2. Bacteria capture efficiency of MNPs and Ag@MNPs.

\subsection{SERS enhancement of Ag@MNPs}

Strong and stable SERS signal was obtained in the treatment of R6G with Ag@MNPs, proving the SERS enhancement by Ag@MNPs nanocomposite, as illustrated in Fig. 3A. Since R6G is a fluorescent xanthene derivative that possesses strong Raman effect when excitation laser emitting into its adsorption band (Michaels et al., 1999), it was employed here to validate the enhancement of Ag@MNPs on Raman scattering. The predominant Raman shifts of R6G were at 1185, 1498, 1367 and $1310 \mathrm{~cm}^{-1}$ attributing to in-plane C-C stretch vibrations, $611 \mathrm{~cm}^{-1}$ for C-C-C ring in-plane bend vibrations, and $772 \mathrm{~cm}^{-1}$ for $\mathrm{C}-\mathrm{H}$ out-of-plane bend vibrations (Hildebrandt \& Stockburger, 1984). The Raman spectra intensities of $\mathrm{R} 6 \mathrm{G}$ characteristic peaks with $100 \%$ laser power excitation ranged from $1390.28\left(611 \mathrm{~cm}^{-1}\right)$ to 4238.28 at $\left(1365 \mathrm{~cm}^{-1}\right)$ when $\mathrm{R} 6 \mathrm{G}$ concentration was $10^{-6} \mathrm{M}$. Treated 
with Ag@MNPs, strong SERS signals were identified with only 1\% laser power. The six key Raman shift peaks included 611, 772, 1185, 1295, 1367 and $1498 \mathrm{~cm}^{-1}$, similar to normal R6G Raman spectra. Different from conventional SERS analysis dropping R6G onto SERS active substrates (Nie \& Emory, 1997), we directly mixed R6G with Ag@MNPs suspension and allowed their interaction in aquatic phase. The harvesting of Ag@MNPs via permanent magnet significantly concentrated R6G on the magnetic spot to achieve strong SERS signal. The Raman signal enhancement of Ag@MNPs was evaluated by the enhancement factor (EF), as calculated by Equation (1):

$$
\mathrm{EF}=I_{S E R S} / I_{\text {Normal }}
$$

where $I_{S E R S}$ is the Raman signal intensities of R6G with Ag@MNPs at $1 \%$ laser power; $\mathrm{I}_{\text {Normal }}$ is Raman signal intensities of $10^{-6} \mathrm{M}$ pure $\mathrm{R} 6 \mathrm{G}$ at $1 \%$ laser power.

(A)

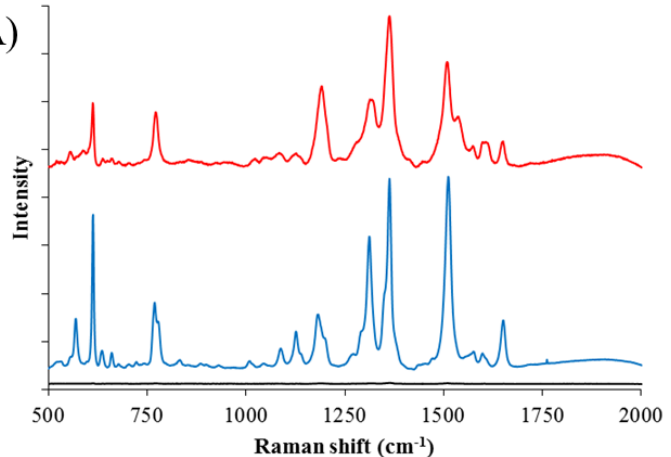

$1 \mu \mathrm{M}$ R6G $1 \%$ power $1 \mu \mathrm{M}$ R6G $100 \%$ power

(C)

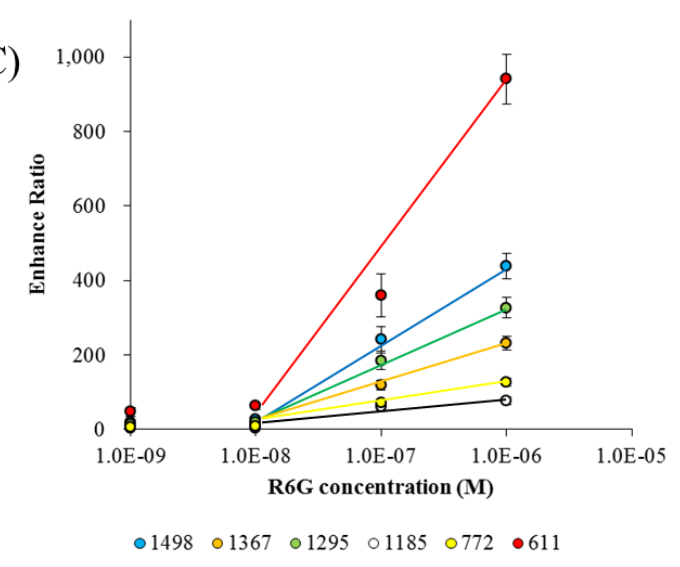

(B)

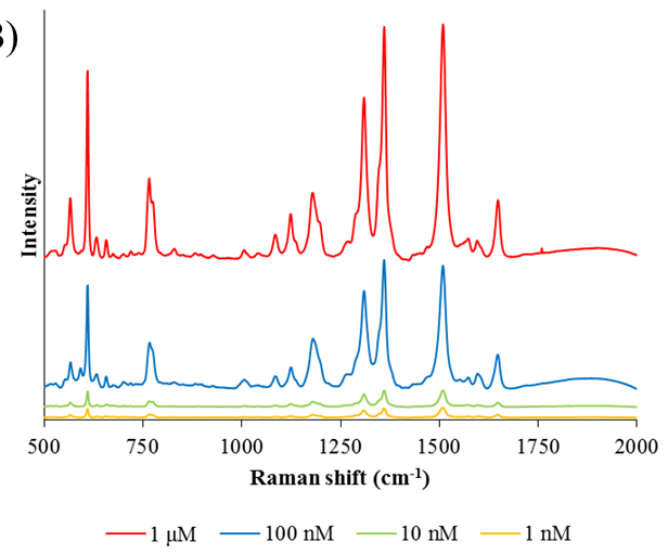

○ $1498 y=7.89 \times 10^{8} x+162, R^{2}=0.9362$

$01367 y=3.36 \times 10^{8} x+112, R^{2}=0.7991$

$01295 \mathrm{y}=2.48 \times 10^{8} \mathrm{x}+85, \mathrm{R}^{2}=0.7816$

$\circ 1185 y=1.82 \times 10^{8} x+54, R^{2}=0.8363$

$0772 y=0.96 \times 10^{8} x+32, R^{2}=0.7939$

- $611 \mathrm{y}=0.51 \times 10^{8} \mathrm{x}+29, \mathrm{R}^{2}=0.5164$

Fig. 3. R6G SERS spectra with Ag@MNPs. (A) Raman spectra of pure R6G and R6G with Ag@MNPs. (B) R6G SERS spectra of different concentrations. (C) Calibration curve of R6G SERS intensity.

For all the tested R6G concentrations $\left(10^{-9}\right.$ to $\left.10^{-6} \mathrm{M}\right)$, strong SERS signals were detected (Fig. 3B). For instance, the Raman intensity of $10^{-6} \mathrm{M}$ R6G with Ag@MNPs with $1 \%$ laser 
power was about 1.5 times higher than that of $10^{-6} \mathrm{M}$ pure R6G with $100 \%$ laser power. We therefore proved that Ag@MNPs were SERS active substrates. From the calculation, the Raman signal of peak $611 \mathrm{~cm}^{-1}$ was enhanced nearly $10^{3}$ times by Ag@MNPs when R6G concentration was $10^{-6} \mathrm{M}$, followed by $1498 \mathrm{~cm}^{-1}$ (439 times), $1295 \mathrm{~cm}^{-1}$ (327 times), 1367 $\mathrm{cm}^{-1}$ (232 times), $772 \mathrm{~cm}^{-1}$ (127 times) and $1185 \mathrm{~cm}^{-1}$ (77 times). As illustrated in Fig. 3C, the SERS intensity of each characteristic peak was positively correlated with the R6G concentrations, with a quantitative range from $10^{-8} \mathrm{M}$ to $10^{-6} \mathrm{M}$. The limit of detection of R6G SERS with magnetic Ag@MNPs assay was $10^{-9} \mathrm{M}$, when the enhancement factor was 15 and distinguishable from the background, although the peaks of $772 \mathrm{~cm}^{-1}$ and $1185 \mathrm{~cm}^{-1}$ were non-detectable.

\subsection{In situ bacteria detection by SERS}

Different from conventional SERS detecting bacteria, we developed a magnetic SERS assay for the rapid screening of bacterial cells in aquatic phase. The Ag-coating did not affect the electrostatic interaction between MNPs and bacteria, allowing the non-selective capture and further enrichment by magnet. The bacteria were detected and quantified by the sensitive plasmonic Ag@MNPs SERS.

Bacterial SERS spectra varied from spot to spot due to the heterogeneous distribution of Ag@MNPs and bacterial cells at low concentration. The SERS spectra of individual cells were then randomly collected and the results demonstrated its high reproducibility. Fig. 4 showed the significant enhancement of Raman signal by Ag@MNPs assay. With 1\% laser power, the enhancement factor of Ag@MNPs was similar for E. coli and A. baylyi, around 50-100 times compared to pure bacterial cells. It was significantly lower than that of R6G $\left(10^{2}\right.$ to $10^{3}$ as discussed above), attributing to the complicated structure and different functional groups of bacterial cell membrane. The main SERS shifts of A. baylyi and E. coli included 660, 731, 964, 1210, 1251, 1325 and $1584 \mathrm{~cm}^{-1}$. The band with the highest SERS intensity was $731 \mathrm{~cm}^{-1}$, explained by the ring breathing of adenine. The bands at 1210 and $1251 \mathrm{~cm}^{-1}$ were caused by Amide III of proteins (Tian et al., 2012). The band at $1325 \mathrm{~cm}^{-1}$ was contributed not only from nucleic acid bases adenine and guanine, but also from aromatic amino acid tyrosine (Cui et al., 2015; López-Díez \& Goodacre, 2004). Ring stretch vibration led to the band at $1584 \mathrm{~cm}^{-1}$ which was weaker than the other SERS peaks (Giese \& McNaughton, 2002). For the band at $964 \mathrm{~cm}^{-1}$, previous studies tentatively assigned it to the C-N stretch (Cui et al., 2013). Meanwhile, the band at $660 \mathrm{~cm}^{-1}$ is construed as a discriminative peak of guanosine in bacterial SERS spectra (Cui et al., 2015). 


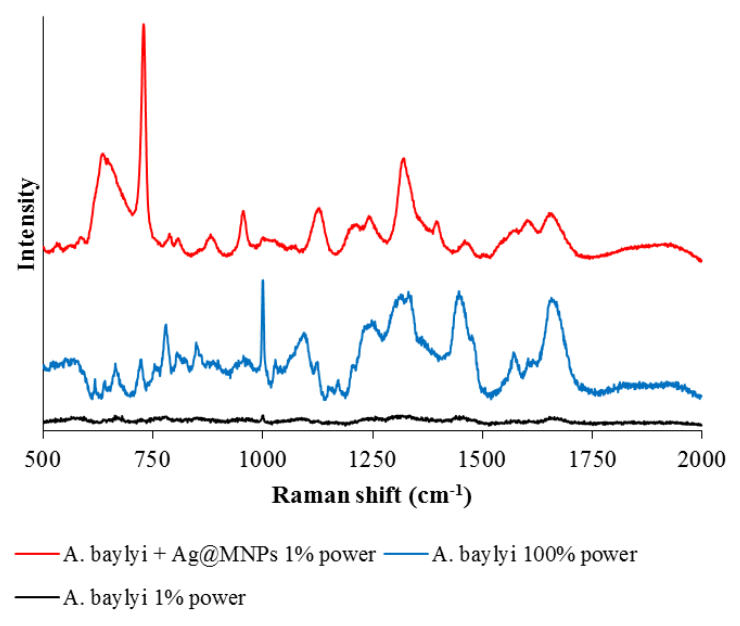

(A)

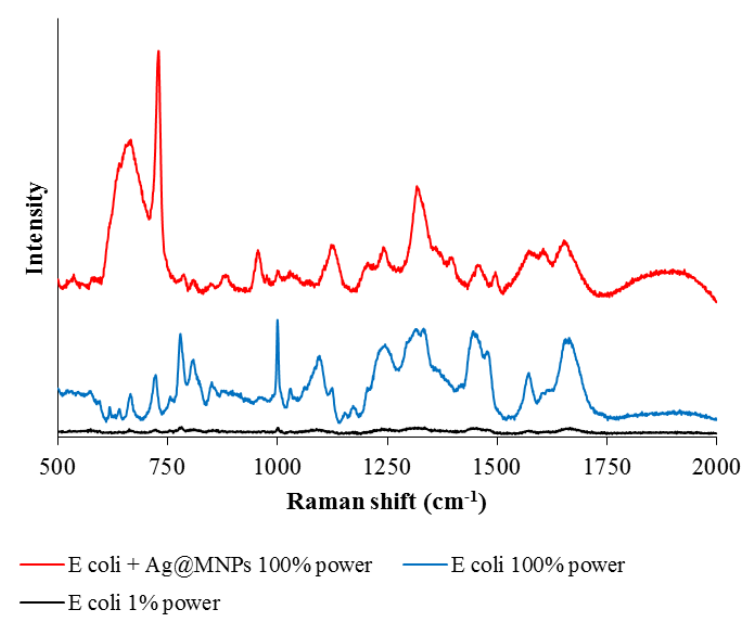

(B)

Fig. 4. Raman and SERS spectra of bacteria. (A) for A. baylyi and (B) for E. coli.

Compared to normal Raman spectra of $A$. baylyi and E. coli, we found different Raman spectra profiles of Ag@MNPs SERS. For instance, the most obvious band for normal Raman spectra of both bacteria was $1003 \mathrm{~cm}^{-1}$ attributing to polysaccharide (Jarvis \& Goodacre, 2004), which was not enhanced by Ag@MNPs. It might be explained by the favourable binding of Ag@MNPs to some specific extracellular molecules (Kahraman et al., 2011), such as adenine and guanine. Meanwhile, the SERS spectra changed slightly at different bacterial concentration, explained by the change from sub-monolayer coverage to full monolayer coverage (Cheng et al., 2012). Thus, the SERS intensity and characteristic bands of bacteria via Ag@MNPs might be used to quantify bacterial concentration. In the present work, the direct limited of bacteria detection via normal Raman in aquatic phase was $10^{8} \mathrm{CFU} / \mathrm{mL}$, while it was significantly improved to $10^{5} \mathrm{CFU} / \mathrm{mL}$ when magnetically captured and enriched by Ag@MNPs.

\section{Conclusion}

For the first time in this study, we proposed and proved the novel concept of capturing bacteria from drinking water and fast detecting their concentration via SERS on magneticcontrollable Ag@MNPs. The results indicated that the bacterial cells were effectively captured by Ag@MNPs and then magnetically enriched for SERS analysis. The Raman intensity was enhanced $10^{2}-10^{3}$ times when R6G was used as the standard chemical and the limit of detection was $10^{-9} \mathrm{M}$ with SERS active substrate Ag@MNPs. This magnetic SERS assay achieved high sensitivity $\left(10^{5} \mathrm{CFU} / \mathrm{mL}\right)$ and rapid screening $(<15 \mathrm{~min})$ to diagnose 
bacteria in water samples. With further fabrication and instrumentation, this technique provides opportunities in diagnosing pathogens in other environmental or clinical samples.

\section{Acknowledgement}

The authors would like to thank National Natural Science Foundation of China (No. 41301331) for financial support. The authors are thankful to Chinese Scholarships Council (CSC) for providing studentship.

\section{References}

[1] An Q., Zhang P., Li J.-M., Ma W.-F., Guo J., Hu J., Wang C.-C., Silver-coated magnetite-carbon core-shell microspheres as substrate-enhanced SERS probes for detection of trace persistent organic pollutants, Nanoscale, 2012, 4, 5210-5216.

[2] Chan J.W., Esposito A.P., Talley C.E., Hollars C.W., Lane S.M., Huser T., Reagentless identification of single bacterial spores in aqueous solution by confocal laser tweezers Raman spectroscopy, Anal. Chem., 2004, 76, 599-603.

[3] Cheng H.W., Huan S.Y., Yu R.Q., Nanoparticle-based substrates for surface-enhanced Raman scattering detection of bacterial spores, The Analyst, 2012, 137, 3601-8.

[4] Chu Y.W., Engebretson D.A., Carey J.R., Bioconjugated Magnetic Nanoparticles for the Detection of Bacteria, J. Biomed. Nanotechnol., 2013, 9, 1951-1961.

[5] Cui L., Chen P., Chen S., Yuan Z., Yu C., Ren B., Zhang K., In situ study of the antibacterial activity and mechanism of action of silver nanoparticles by surfaceenhanced Raman spectroscopy, Anal. Chem., 2013, 85, 5436-43.

[6] Cui L., Chen P., Zhang B., Zhang D., Li J., Martin F.L., Zhang K., Interrogating chemical variation via layer-by-layer SERS during biofouling and cleaning of nanofiltration membranes with further investigations into cleaning efficiency, Water Res., 2015, 87, 282-291.

[7] Dharmasiri U., Witek M.A., Adams A.A., Osiri J.K., Hupert M.L., Bianchi T.S., Roelke D.L., Soper S.A., Enrichment and Detection of Escherichia coli O157:H7 from Water Samples Using an Antibody Modified Microfluidic Chip, Anal. Chem., 2010, 82, 28442849.

[8] Ennen I., Albon C., Weddemann A., Auge A., Hedwig P., Wittbracht F., Regtmeier A., Akemeier D., Dreyer A., Peter M., Jutzi P., Mattay J., Mitzel N., Mill N., Hutten A., 
From Magnetic Nanoparticles to Magnetoresistive Biosensors, Acta Phys. Pol. A, 2012, $121,420-425$.

[9] Giese B., McNaughton D., Density functional theoretical (DFT) and surface-enhanced Raman spectroscopic study of guanine and its alkylated derivatives Part 2: Surfaceenhanced Raman scattering on silver surfaces, Phys. Chem. Chem. Phys., 2002, 4, 51715182.

[10] Grow A.E., Wood L.L., Claycomb J.L., Thompson P.A., New biochip technology for label-free detection of pathogens and their toxins, J. Microbiol. Methods, 2003, 53, 221233.

[11]Hildebrandt P., Stockburger M., Surface-enhanced resonance Raman spectroscopy of Rhodamine 6G adsorbed on colloidal silver, The Journal of Physical Chemistry, 1984, 88, 5935-5944.

[12]Huang Y.-F., Wang Y.-F., Yan X.-P., Amine-Functionalized Magnetic Nanoparticles for Rapid Capture and Removal of Bacterial Pathogens, Environ. Sci. Technol., 2010, 44, 7908-7913.

[13] Ibekwe A.M., Watt P.M., Grieve C.M., Sharma V.K., Lyons S.R., Multiplex fluorogenic real-time PCR for detection and quantification of Escherichia coli O157 : H7 in dairy wastewater wetlands, Appl. Environ. Microbiol., 2002, 68, 4853-4862.

[14]Jarvis R.M., Goodacre R., Discrimination of Bacteria Using Surface-Enhanced Raman Spectroscopy, Anal. Chem., 2004, 76, 40-47.

[15]Joo J., Yim C., Kwon D., Lee J., Shin H.H., Cha H.J., Jeon S., A facile and sensitive detection of pathogenic bacteria using magnetic nanoparticles and optical nanocrystal probes, The Analyst, 2012, 137, 3609-3612.

[16]Kahraman M., Keseroglu K., Culha M., On Sample Preparation for Surface-Enhanced Raman Scattering (SERS) of Bacteria and the Source of Spectral Features of the Spectra, Appl. Spectrosc., 2011, 65, 500-506.

[17]López-Díez E.C., Goodacre R., Characterization of Microorganisms Using UV Resonance Raman Spectroscopy and Chemometrics, Anal. Chem., 2004, 76, 585-591.

[18]López Pérez J.A., López Quintela M.A., Mira J., Rivas J., Charles S.W., Advances in the Preparation of Magnetic Nanoparticles by the Microemulsion Method, The Journal of Physical Chemistry B, 1997, 101, 8045-8047.

[19]Lehtola M.J., Loades C.J., Keevil C.W., Advantages of peptide nucleic acid oligonucleotides for sensitive site directed 16S rRNA fluorescence in situ hybridization 
(FISH) detection of Campylobacter jejuni, Campylobacter coli and Campylobacter lari, $J$. Microbiol. Methods, 2005, 62, 211-219.

[20]Lin Z., Xu Y., Zhen Z., Fu Y., Liu Y., Li W., Luo C., Ding A., Zhang D., Application and reactivation of magnetic nanoparticles in Microcystis aeruginosa harvesting, Bioresource Technology, 2015, 190, 82-88.

[21]Luis Corchero J., Villaverde A., Biomedical applications of distally controlled magnetic nanoparticles, Trends Biotechnol., 2009, 27, 468-476.

[22] Mandal M., Kundu S., Ghosh S.K., Panigrahi S., Sau T.K., Yusuf S.M., Pal T., Magnetite nanoparticles with tunable gold or silver shell, J. Colloid Interface Sci., 2005, 286, 187-94.

[23] Martin F.L., Kelly J.G., Llabjani V., Martin-Hirsch P.L., Patel I.I., Trevisan J., Fullwood N.J., Walsh M.J., Distinguishing cell types or populations based on the computational analysis of their infrared spectra, Nature Protocols, 2010, 5 (11), 1748-1760.

[24] Michaels A.M., Nirmal M., Brus L.E., Surface enhanced Raman spectroscopy of individual rhodamine 6G molecules on large Ag nanocrystals, J. Am. Chem. Soc., 1999, 121, 9932-9939.

[25]Nie S., Emory S.R., Probing Single Molecules and Single Nanoparticles by SurfaceEnhanced Raman Scattering, Science, 1997, 275, 1102-1106.

[26] Ozdemir C., Akca O., Medine E.I., Demirkol D.O., Unak P., Timur S., Biosensing Applications of Modified Core-Shell Magnetic Nanoparticles, Food Anal. Meth., 2012, 5, 731-736.

[27]Penna V.T.C., Martins S.A.M., Mazzola P.G., Identification of bacteria in drinking and purified water during the monitoring of a typical water purification system, BMC Public Health, 2002, 2.

[28]Porter M.D., Lipert R.J., Siperko L.M., Wang G., Narayanana R., SERS as a bioassay platform: fundamentals, design, and applications, Chem. Soc. Rev., 2008, 37, 1001-1011.

[29]Rompre A., Servais P., Baudart J., de-Roubin M.R., Laurent P., Detection and enumeration of coliforms in drinking water: current methods and emerging approaches, $J$. Microbiol. Methods, 2002, 49, 31-54.

[30] Sau T.K., Murphy C.J., Room temperature, high-yield synthesis of multiple shapes of gold nanoparticles in aqueous solution, J. Am. Chem. Soc., 2004, 126, 8648-8649.

[31] Shen J., Zhu Y., Yang X., Zong J., Li C., Multifunctional $\mathrm{Fe}_{3} \mathrm{O}_{4} @ \mathrm{Ag} / \mathrm{SiO}_{2} / \mathrm{Au}$ CoreShell Microspheres as a Novel SERS-Activity Label via Long-Range Plasmon Coupling, Langmuir, 2013, 29, 690-695. 
[32] Sun C., Lee J.S.H., Zhang M., Magnetic nanoparticles in MR imaging and drug delivery, Adv. Drug Delivery. Rev., 2008, 60, 1252-1265.

[33] Szewzyk U., Szewzyk R., Manz W., Schleifer K.H., Microbiological safety of drinking water, Annu. Rev. Microbiol., 2000, 54, 81-127.

[34]Tian H., Zhuang G., Ma A., Jing C., Arsenic interception by cell wall of bacteria observed with surface-enhanced Raman scattering, J. Microbiol. Methods, 2012, 89, 153 158.

[35]Wang H., Zhou Y., Jiang X., Sun B., Zhu Y., Wang H., Su Y., He Y., Simultaneous Capture, Detection, and Inactivation of Bacteria as Enabled by a Surface-Enhanced Raman Scattering Multifunctional Chip, Angewandte Chemie-International Edition, 2015, 54, 5132-5136.

[36] World Health Organization. 2011. Guidelines for drinking-water quality. 4th ed. WHO Library Cataloguing-in-Publication Data.

[37]Xu Y., Li C., Zhu X., Huang W.E., Zhang D., Application of magnetic nanoparticles in drinking water purification, Environ. Eng. Manage. J., 2014, 13, 2023-2029.

[38] Yang T., Guo X., Wang H., Fu S., Wen Y., Yang H., Magnetically optimized SERS assay for rapid detection of trace drug-related biomarkers in saliva and fingerprints, Biosens. Bioelectron., 2015, 68, 350-357.

[39]Zhang D., Fakhrullin R.F., Ozmen M., Wang H., Wang J., Paunov V.N., Li G., Huang W.E., Functionalization of whole-cell bacterial reporters with magnetic nanoparticle, Microb Biotechnol, 2011, 4, 89-97.

[40]Zhang L., Xu J., Mi L., Gong H., Jiang S., Yu Q., Multifunctional magnetic-plasmonic nanoparticles for fast concentration and sensitive detection of bacteria using SERS, Biosens. Bioelectron., 2012, 31, 130-136.

[41]Zhao X., Li H., Ding A., Zhou G., Sun Y., Zhang D., Preparing and characterizing $\mathrm{Fe}_{3} \mathrm{O}_{4} @$ cellulose nanocomposites for effective isolation of cellulose-decomposing microorganisms, Mater. Lett., 2016, 163, 154-157. 